\title{
A COMPARATIVE STUDY ON MITE INFECTED COCONUT TREES IN CHRIST COLLEGE CAMPUS
}

\author{
P. Anand, J. Michael Israel, Ankit Bachhawat, Vandana \\ Garima Gujadhur, Chriss K. George* \& Antoney P.U**
}

\section{Introduction}

Coconut mite Aceria (Eriophyes) guerreronis (Keifer) of the family Eriophyidae has been posing serious problems to the production of coconut in Kerala from 1997 onwards. From an infestation which was confined to a few plantations in Ernakulam District in 1997, the pest has now spread extensively in the State. The attack has caused drastic reduction in coconut production, playing havoc to the coconut based economy of Kerala. Of late the problem is widespread in many parts of Karnataka and the whole of south India. Coconut perianth mite is a microscopic, whitish organism, $0.20-0.25 \mathrm{~mm}$ long and cylindrical. The species and genus is distinguished by the presence of a median pit just posterior to the prodorsal shield. To a naked eye the mite colonies look like white powder sprinkled here and there. The pest is infesting the young buttons in the post-fertilization period. The mites which settle at the interspaces between the perianth and button feed on the sap of

* B.Sc. (CBZ) Students of Christ College, Bangalore.

** Department of Zoology, Christ College, Bangalore. 
the perianth and button. The life cycle of the mite is completed with in $8-10$ days. The population of the mite increases 100 fold in about 10 days and in a matter of less than a month, the population will be enormous. The symptoms are manifested about one month after the initial colonization. At this time, a small yellow halo develops around the edge of the perianth covering the button. In many cases, when the perianth is removed, a pinkish band can be seen on its inner side. A few days later, the halo develops into triangular yellowish discoloration pointing towards the distal end. The discoloration can also take the shape of thin stripes. Within two months after pollination, the 'hallow' fully develops and becomes conspicuous. During this period, some buttons show browning and necrosis on the periphery of the perianth. The yellow discoloration later turns brown and results in warty shrinking of the husk. At this stage, the husk develops cracks, cuts, gummosis and freckles. When the infestation is severe, nut fall may occur. The nuts which continue to remain in the bunch are undersized and malformed, the degree of malformation varying with infestation. At maturity the husk of the nut is very tight and shrunken causing difficulty in dehusking.

\section{Objectives}

- To study the number of coconut trees affected in Christ college campus

- To bring awareness of the diseases and thereby help control

- To encourage natural cultivation practices

- To emphasize the need to avoid pesticides

\section{Study Area}

Located in the southern part of Bangalore city; Dharmaram- Christ college campus is spread in about 100 acres with few educational and residential buildings interspersed among a vast stretch of coconut grooves, Avenue trees and other fruiting trees like mango trees, sapota, etc. A few artificial water bodies are also present in the campus. Two sites in the campus of Christ College were selected for this study. Study site- 1 is the birds' park on the southern side of block II. There were 45 trees in all and 2 water bodies and the area is well watered. The study was however done on the 10 coconut trees in this site. The trees are very much close to each other. The second site of study was the garden behind the main block of Christ College. The study was conducted on all the 8 trees present there. No water bodies in the area and the trees are spread apart. 


\section{Methodology}

The siters of study were visited by all the members thrice in a month for two months. We counted the number of trees, and the number of coconuts that were infected and their location with reference to other shade trees and water bodies etc. No extra props were used by us for this project.

\section{Results}

Site no 1:

In Birds Park out of 10 coconut trees 7 were infected

\begin{tabular}{|c|c|}
\hline No. of tree & Coconuts infected \\
\hline 1 & 3 \\
2 & 2 \\
3 & 0 \\
4 & 15 \\
5 & 1 \\
6 & 0 \\
7 & 14 \\
8 & 7 \\
9 & 0 \\
10 & \\
\hline
\end{tabular}

\begin{tabular}{|c|c|l|}
\hline No. of trees & Coconuts infected & Places where found \\
\hline 1 & 3 & Near water body \\
2 & 2 & Near water body \\
3 & 0 & In full sun \\
4 & 15 & Shady place \\
5 & 1 & In full sun \\
6 & 0 & In full sun \\
7 & 14 & Shady place \\
8 & 13 & Shady place \\
9 & 7 & Partial sun \\
10 & 0 & In full sun \\
\hline
\end{tabular}


Site-2: Out of eight trees studied 6 were infected

\begin{tabular}{|c|c|}
\hline No. of tree & Coconuts infected \\
\hline 1 & 4 \\
2 & 4 \\
3 & 9 \\
4 & 13 \\
5 & 5 \\
6 & 0 \\
7 & 10 \\
8 & 0 \\
\hline
\end{tabular}

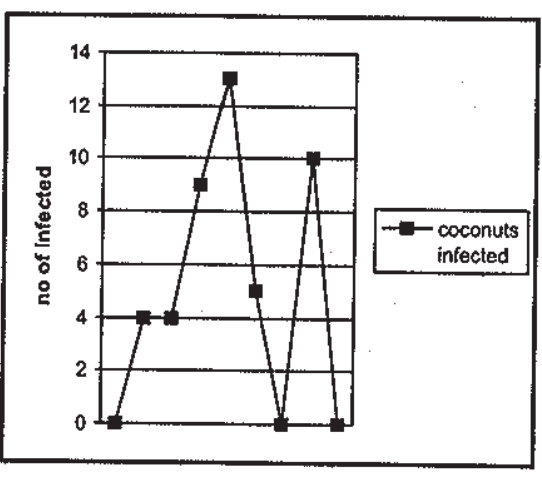

\begin{tabular}{|c|c|l|}
\hline No. of trees & Coconuts infected & Location \\
\hline 1 & 4 & Partial sun \\
2 & 4 & Partial sun \\
3 & 9 & Shady place \\
4 & 13 & Shady place \\
5 & 5 & Partial sun \\
6 & 0 & Full sun \\
7 & 10 & Shady place \\
8 & 0 & Full sun \\
\hline
\end{tabular}

\section{Discussion \& Conclusion}

Behind main block coconut trees which are infected does not get appropriate sunlight are severely infected by mite disease as compared to trees which receives appropriate amount of sunlight. From this survey we deduce that the trees, which do not receive adequate sunlight, are more prone to mites than trees, which receive adequate sunlight. Hence it is advisable to avoid shade trees and to maintain a reasonable tree to tree distance in coconut grooves to overcome the attack of mites. 


\section{Annexure}
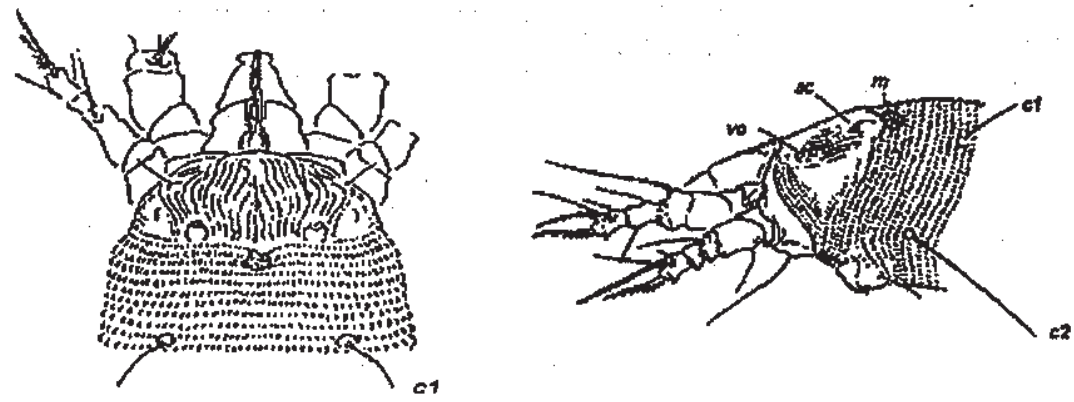

Fig 1: Coconut mite

Antero-dorsal view

Antero-lateral view

Ve - external vertical seta; $m$ - median pit; sc - scapular seta
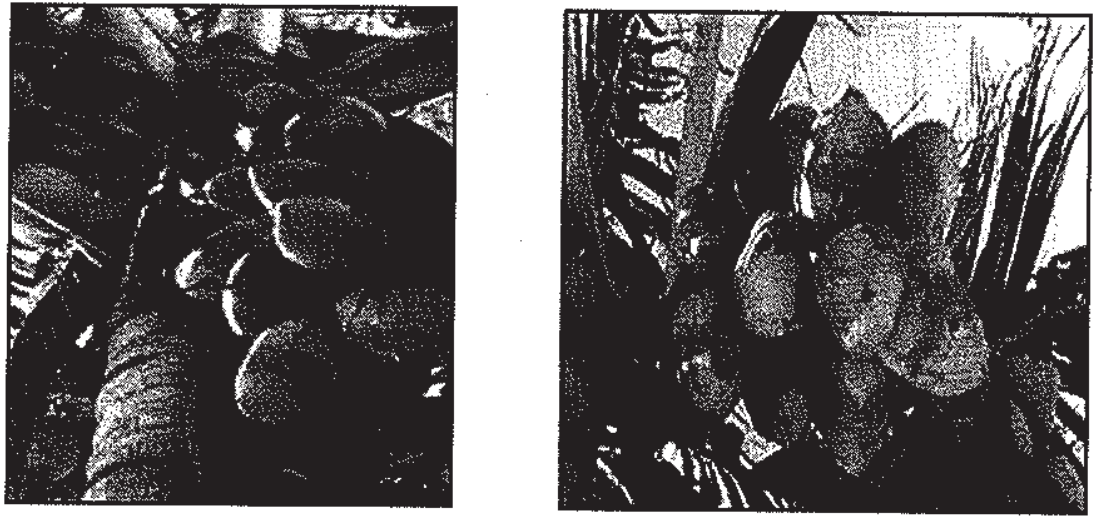

Figure 2 : Coconuts affected with the mite disease

\section{References}

1. Umapathy and Mohanasundaran (2002) Rare species of eriophyid mites from Southem India; Zoos'Print Journal, Pp771.774,

2. Ekambaranath lyer, A Manual of Zoology

3. hitp://wnw.kov.edu/coconutmites.htm

4. http://wnw, ambergriscoye,com/cocopalms/disease.html 